\title{
ALCOY Y SUS BILLETES. UNA ALTERNATIVA FRENTE A LA CARENCIA DE MONEDA FRACCIONARIA DURANTE LA GUERRA CIVIL (1936-1939)
}

José Miguel Santacreu Soler

El problema de la carencia de moneda fraccionaria en Alcoy durante la Guerra Civil ${ }^{1}$, abundantemente constatado en diversas fuentes de carácter local como son las Actas del Consejo Municipal ${ }^{2}$ y la prensa de la época - diario Humanidad $d^{\beta}$-, no es un caso aislado. Dicho problema fue un hecho común, a lo largo de la contienda, en toda la zona republicana como se deduce de los trabajos de Calicó ${ }^{4}$, Conde ${ }^{5}$, Vicenti 6 , del Banco de España ${ }^{7}$..., siendo varias, siempre dentro de una interacción, las

1 Sobre la Guerra Civil en Alcoy, vide Berenguer, J., Historia de Alcoy, III, Alcoy, 1977, págs. 235-370; Coloma, R., Episodios Alcoyanos de la Guerra de España 1936-1939, Alicante, 1980; Ramos, V., La Guerra Civil 1936-1939 en la provincia de Alicante, 3. ${ }^{2}$ ed., Alicante, 1974.

2 Mi agradecimiento a Donato Garrigós Moreno, auxiliar administrativo del Ayuntamiento de Alcoy, por su gentileza a la hora de permitirme consultar dichas actas.

3 Diario local publicàdo en Alcoy desde el 1 de noviembre de 1936 hasta el 29 de marzo de 1939 (Archivo Municipal de Alcoy).

4 Calico, F. X., La numismática de la Guerra Civil española, exposición sobre dicha guerra del Ministerio de Cultura, 1980, págs. 67-70.

5 Conde, 1., Billete de cincuenta pesetas, emitido en Gijón, en septiembre de 1937, Actas del I Congreso Nacional de Numismática 1972, Zaragoza, 1974, páginas 449-453.

6 ViCEnTI, J. A., La peseta, catálogo, 12. a ed., Madrid, 1977.

7 Banco de España, Los Billetes del Banco de España, 3. ${ }^{a}$ ed., Madrid, 1979. 
causas que lo motivaron y muy distinta la mayor o menor repercusión de las mismas en unas u otras zonas de la España republicana, atendiendo al grado de dificultad existente para establecer una comunicación física con el gobierno central.

Antes de abordar el breve análisis de las causas considero oportuno aclarar una cuestión sin la cual resultaría imposible comprender las directrices del presente trabajo. ¿Cuál era el potencial monetario circulante de la República al estallar la guerra? Desde el decreto del 19 de octubre de 1868, en que se fijó la PESETA, dividida en 100 céntimos, como unidad monetaria nacional, se desarrollaron en nuestro país una serie de acuñaciones en oro para los valores de $100,25,20$ y 10 ptas., en plata para los de $5,2,1,0,50$ y 0,20 ptas. y en cobre para los $10,5,2$ y 1 cts. respectivamente; a las que se añadirían los 25 cts. de cupro-níquel tras el decreto del 9 de enero de $1915^{8}$. A esto se suman los billetes emitidos por el Banco de España, desde que éste lograra el privilegio de único emisor en 1874, para valores de 1.000, 500, 50 y 25 ptas. respaldados por una cobertura metálica extraida de las acuñaciones monetales de oro o de plata, según la época, ya que estos billetes son simples cheques al portador, sin más ${ }^{9}$.

El oro dejó de circular hacia $1914^{10}$, tal vez a causa de la depreciación de la peseta ${ }^{11}$. Es de suponer que la desaparición de los valores acuñados en oro no causó graves problemas de circulación monetaria ya que venian realizándose, por parte del Banco de España, emisiones de billetes con valores de 100, 50 y 25 ptas. respectivamente ${ }^{12}$ que paliaron la carencia de las pie-

8 Cf. CALICO, O. C., y VICENTI, O. c. Para ampliar el origen de la peseta, vide FERNÁNDEZ, C., La creación de la peseta en la evolución del sistema monetario de 1847 a 1868; Anes, Ensayos sobre la economía española a mediados del siglo XIX, Madrid, 1970, págs. 147-186.

9 Vide BANCo de EsPaña, O. $C$.

10 Cf. GlL, O., Historia Universal de la Moneda, Madrid, 1974, pág. 221.

11 Vide VICENS, J., Historia de España y América social y económica, V, 2. ${ }^{a}$ reed., Barcelona, 1977, págs. 104-105.

12 Banco de España, o. C., págs. 123-134. 
zas de oro. Asi quedaba la plata, el cobre y el tardio cupro-níquel como base metálica del sistema monetario español, pese a que en la época de la dictadura de Primo de Rivera se soñase de nuevo con implantar el patrón oro ${ }^{11}$.

Al estallar la Guerra Civil en julio de 1936 el potencial monetario circulante para toda España se componía de los billetes emitidos por el Banco de España con valores de 1.000 (3.646.000 billetes). 500 (1.602.000 b.), 100 (32.000.000 b.), 50 (18.640.000 b.) y 25 (17.780.000 b.) ptas. ${ }^{13}$ y de las monedas, acuñadas por el Estado, de plata con valores de 5 (210.437.486 piezas), 2 (78.159.769 p.), 1 (111.544.106 p.) y 0,50 (33.600.196 p.) ptas. ${ }^{14}$, de cupro-niquel con el valor de 25 cts. (32.000.099 p.) y de cobre con valores de 10 (324.708.553 p.), 5 (444.701.486 p.), 2 (138.386.865 p.) y 1 (1.090.169.399 p.) cts. respectivamente ${ }^{15}$. De forma que el papel, con su connotación de cheque al portador, tenía el monopolio de los valores iguales o superiores a 25 ptas. y el metal el de los valores iguales o inferiores a 5 ptas., observándose una clara división de potestades entre el papel y el metal.

Ahora bien, como los -billetes- del Banco de España eran reembolsables en monedas de plata precisamente de 5 ptas. el banco había de tener siempre disponible una fuerte cantidad de monedas efectivas, por lo que no es posible señalar cuál era el volumen real de las monedas en circulación ${ }^{16}$. Más aún, con la guerra España se dividió en dos bandos que se repartieron el numerario existente, atendiendo a su situación geográfica, y por otra parte los particulares que no creían en los bancos de depósito atesoraban los billetes y monedas bajo los ladrillos de sus casas con lo que se agrava mucho más el problema de saber cuál era el volumen real del circulante monetario, tanto en una

13 Ibíd., pág. 279.

14 Desprecio las 0,20 pesetas por ser ínfima su cantidad.

15 Calico, o. c., pág. 64, y Castan-Cayon, Las Monedas Hispano Musulmanas y Cristianas 711-1981, Madrid, 1980, págs. 1122-1142.

16 Cf. Calico, o. C., pág. 64. 
zona como en la otra del conflicto; de ahí que nosotros usemos el término potencial monetario circulante.

A distinto nivel hay que decir que la España republicana tuvo unas ventajas sobre la España rebelde: las herencias anteriores a julio de 1936. Me explico: la Caja Central del Banco de España quedó dentro del área dominada geográficamente por los republicanos. Esta Caja conservaba en sus arcas todos aquellos billetes que no fueron puestos en circulación antes del 18 de julio de 1936 y el Banco de España, sometido al gobierno de la República, podia disponer al comienzo de la guerra de una enorme cantidad de billetes de $1.000,500,100,50$ y 25 ptas. respectivamente ${ }^{17}$. Y no tenía a su disposición solamente estos billetes sino que, además, heredó el proyecto, casi elaborado, de los certificados de plata de 1935 con valores de 10 y 5 ptas. respectivamente. No se trataba de billetes, dentro de la concepción que sobre ellos estamos manejando, sino que eran una especie de certificados que suplirian circunstancialmente las monedas acuñadas por el estado, ante el temor de que las monedas de 5 ptas. (Ilamadas duros de plata) desaparecieran de la circulación por ser desmonetizadas buscando un beneficio en la venta del metal a causa de la pérdida del poder adquisitivo de la peseta, unida al aumento en el precio de la plata ${ }^{18}$.

Una de las causas fundamentales de dicha crisis de numerario fue, sin duda, la situación de anormalidad creada por el conflicto bélico con las consiguientes dificultades en los transportes y fronteras, destrucciones y otras alteraciones de la vida normal del país. Conde, en su trabajo ${ }^{19}$, la considera esencial para explicar el problema monetario; pero dicha causa, aunque fundamental para entender la crisis del numerario en su conjunto, tanto para valores fraccionarios como no fraccionarios, no resulta especialmente significativa en el caso de Alcoy ya que

17 Vide Banco de España, o. c., pág. 279.

18 lbid., págs. 274-275.

19 Conde, o. c., pág. 449. 
aquí el problema de la fälta de circulante sólo afectó a la moneda fraccionaria y se derivó, como veremos más adelante, de otro tipo de causas. En cambio, en Gijón, el caso que estudia Conde, la crisis alcanzó a todo tipo de valores debido a su excepcional situación geográfica. La zona del $\mathrm{N}$ de España se encontraba bloqueada por el bando enemigo resultándole muy difícil establecer contacto físico con el gobierno central republicano y disfrutar de sus medidas respecto a la carencia del circulante. Por el contrario, Alcoy, sí que pudo disfrutar de estas soluciones gubernamentales, que luego estudiaremos, gracias a su favorable posición geográfica ${ }^{20}$. A este respecto es muy clarificadora la obra del Banco de España ${ }^{21}$ que analiza, brevemente, el problema monetario de las zonas aisladas por los rebeldes.

Una segunda causa de la crisis fue la mágica desaparición de la plata y el deterioro de los billetes existentes. En el primer caso fue la inflación galopante la que, al motivar una tesorización de monedas preferentemente de plata, originó una rápida retirada de las mismas de los circuitos monetarios que se hizo extensiva incluso, por una especie de mimetismo, a las monedas de cobre y cupro-níquel, colapsando la circulación monetaria, tal como afirma Calicó ${ }^{22}$. Por su parte Gil Farrés ${ }^{23}$ opina que "el gobierno de la República ordenó retirar la plata, y con tal motivo, desde 1937 fueron apareciendo diferentes monedas...". Por desgracia, el autor no entra en mayores consideraciones ni menciona las fuentes de apoyo. He buscado algún dato directo que confirmara dicha teoría, sin fortuna; lo único que he encontrado es una especie de vía subalterna que luego desarrollaremos. En otro de sus trabajos ${ }^{24}$ dice al tratar el sistema moneta-

20 Vide evolución fronteras en Tuñón, M., y GARCiA; M. ${ }^{a}$ C., La Guerra Civil, Historia de España, IX, Labor, 2. ${ }^{2}$ reed., Barcelona, 1983, págs. 243-626; Kramer, A.. La mecánica de la Guerra Civil, Barcelona, 1981.

21 Banco de España, O. c., págs. 290-307.

2.2 Calico, o. c., pág. 65.

23 GIL, O., Historia de la moneda española. Madrid. 1976. pág. 539.

24 GiL, O.. Historia universal de la moneda. o. c.. pág. 221. 
rio español nacido en 1868: "su curso legal se ha mantenido hasta el comienzo de la Guerra Civil de 1936-1939..."; pero, como en su estudio anterior, ni desarrolla el tema ni menciona las fuentes.

Considero, sinceramente, que el verdadero desencadenante de la crisis de moneda fraccionaria en Alcoy fue la desaparición de la plata y la falta de un circulante que la sustituyera. No creo, como lo cree Calicó, que la galopante inflación fuese la causa esencial de la retirada de la plata de los circuitos monetarios. Si ello fuese así había motivos suficientes en $1898^{25}$, en $1914^{26}$ o en $1929^{27}$ para que esta mágica desaparición del susodicho metal ya se hubiera producido. Por esas fechas se dieron deflaciones junto a algunos proyectos de billetes semejantes a los certificados de plata de 1935 en 1898 y 1914. Esta desaparición de la plata durante la guerra fue, más bien, una consecuencia de la interacción de varios hechos. De un lado la tendencia inflacionista, con las tesorizaciones a que daba lugar, de otro la situación de anormalidades creada por el conflicto bélico, con los subsiguientes almacenamientos de valores efectivos bus. cando una seguridad económica para la posguerra; y, más que nada, la postura autodefensiva de la gente ante el decreto del 3 de octubre de 1936 que canalizó la entrega del oro y las divisas particulares al Estado ${ }^{28}$ con el fin de emplear estos valores para financiar la guerra ${ }^{29}$, lo cual supone que el propio gobierno también tesorizó. Pero aún más, si en 1937 los pagos exteriores se hicieron con oro a peso, en 1938 se recurrió a la plata con el mismo $\mathrm{fin}^{30}$. Ello presupone que, con anterioridad, los orga-

25Vide Banco de España. O. C.. pág. 196.

26 Ibíd., pág. 235.

27 Vide VICENS, J., O. C., pág. 105.

28 Gaceta de Madrid, 4 de octubre de 1936.

29 Vide VIÑas, A., El oro español en la Guerra Civil, Madrid, 1976.

30 Vide Tuñón, M., y Garcia, M. ${ }^{a}$ C., La financiación de la guerra, o. c., páginas 438-441. 
nismos dirigentes de la República habían recogido esta plata, retirándola de la circulación. Con ello no quiero decir que toda la plata procediese de las monedas; pero supongo que buena parte sí. A la vista de esto ya se puede explicar la desaparición de la plata, que deja de ser una desaparición mágica, porque de un lado atesoran los ciudadanos, con unos escasos medios y, casi siempre, buscando su seguridad, y de otro el propio estado, con sus enormes medios y fines varios, principalmente el de financiar la guerra.

El hecho es que la moneda de plata desapareció del mercado y, con ella, los valores monetales de 5, 2, 1 y 0,50 ptas. Esto causó tal vacío de circulante fraccionario ${ }^{31}$ que obligó a que se buscasen soluciones inmediatas, como veremos más adelante. El gobierno no había previsto la desaparición de toda la base metálica ni poseía una alternativa en billetes como la que anuló las consecuencias negativas de la desaparición del oro en 1914. El estado sí que heredó ${ }^{32}$ el proyecto, casi ultimado, de los certificados de plata de 5 y 10 ptas. respectivamente, por lo que la crisis no afectó a los valores de 5 ptas. ya que existía una alternativa que eliminaba las consecuencias de su desaparición. Por tanto, la crisis de la plata sólo afectó a los valores inferiores a 5 ptas. ya que para dichos valores inferiores no se tenían paliativos a mano.

Por lo que se refiere al deterioro de los billetes existentes, la repercusión fue mucho mayor en las zonas republicanas bloqueadas por el enemigo que, lógicamente, tenian grandes dificultades para establecer contacto con el gobierno central y nutrirse de los billetes que poseía en reserva la Caja Central del Banco de España; por ello, la crisis, alcanzó en estas zonas tanto a los valores fraccionarios como superiores ${ }^{33}$. No era éste el caso de Alcoy ya que al ser menor el problema de las comunicaciones con Madrid los billetes podían ser sustituidos, al menos

31 Vide gráficos I y II.

32 Vide lineas anteriores.

33 Vide CONDE, o. c. 
teóricamente, con mayor facilidad. El hecho es que en Alcoy no se padeció la carencia del circulante monetario igual o superior a 5 ptas. ya que el papel-moneda y los billetes, tanto del Ministerio de Hacienda como del Banco de España, llegaban con relativa facilidad, como veremos más adelante. Por tanto concluimos que esta causa fue secundaria en el caso alcoyano.

Hay que señalar como tercera causa la pasividad de los gobernantes ante la crisis fraccionaria; pasividad que no mostraron frente a los valores superiores. La explicación de esta pasividad demostrada sólo ante valores fraccionarios parece clara. Para dar solución al problema de la carencia de moneda superior, el estado no tuvo más que poner en circulación los billetes que ya había fabricados y guardados en el Banco de España ${ }^{34}$, todos con series anteriores a 1936; pero para dar solución al problema de la carencia de moneda fraccionaria tuvo que elaborar proyectos y efectuar nuevas emisiones, lo cual llevó más tiempo ${ }^{35}$.

Podriamos añadir una cuarta causa, mencionada ya al estudiar la desaparición de la plata: la galopante depreciación de la peseta ${ }^{36}$ que obligó a que se necesitase una mayor cantidad de numerario para poder realizar las transacciones diarias y comerciales. A este respecto es clarificadora la obra del Banco de España al decir que la circulación de los billetes, como consecuencia de la inflación desatada en la zona (republicana), crecía vertiginosamente. De la cifra de 5.399.370.000 pesetas en 30 de junio de 1936, para toda España, se pasó al final de la guerra a 12.754 millones, solamente en la zona republicana, sin contar las series inferiores (a 25 ptas.). Por tanto, fue necesario acudir a nuevas emisiones ${ }^{37}$. De otro lado la inflación motivó los atesoramien-

34 Vide BANCO DE EsPaña, pág. 279.

35 Vide BANCO DE ESPAÑa, pág. 339.

36 Vide Vicens, o. c., pág. 105, y para ampliar Voltes, P., Historia de la economía española en los siglos XIX y XX, 2 v., Madrid, 1974.

37

O. c., pág. 279. 
tos de moneda metálica, como hemos visto líneas atrás, que desaparece del mercado.

Sería necesario desarrollar más ampliamente todas las causas pero nos extenderíamos demasiado por lo que considero suficiente que queden apuntadas. Además, el objetivo de los puntos que acabamos de ver no es el de analizar profundamente las causas sino el de trazar las directrices que nos ayuden a comprender el significado de la emisión de billetes por parte del Ayuntamiento de Alcoy. Idéntico objetivo es el que nos mueve a estudiar las soluciones dadas ante esta necesidad de numerario creada por la crisis que hemos diagnosticado.

Los protagonistas de estas soluciones para la carencia de numerario fueron varios, de una parte el gobierno central republicano y de otra los organismos locales, llámense sucursales del Banco de España, comunidades autónomas, provincias, ayuntamientos, cooperativas, sindicatos, tiendas..., que suplieron las deficiencias de la actuación gubernativa.

Las reacciones del gobierno central ante dicha necesidad de numerario podemos establecerlas a dos niveles, a nivel no fraccionario y a nivel fraccionario. El primero de los niveles abarca los valores iguales o superiores a 5 ptas. Para estos valores el gobierno dio una pronta y rápida solución. De un lado puso en circulación los billetes de $1.000,500,100,50$ y 25 ptas., con series anteriores a 1936, almacenados en el Banco de España ${ }^{38}$; de otro puso en circulación, también, los certificados de plata de 10 y 5 ptas. con emisión de $1935^{39}$. Si esta solución gubernativa se expresa con éxito a nivel general resolviendo el problema de la circulación monetaria para valores no fraccionarios, ello no quiere decir que no falten excepciones como el caso de Gijón que estudia Conde ${ }^{40}$, en donde la carencia de numerario superior no se resolvió con estas medidas; al igual que sucedió en todas aquellas zonas que se encontraban rodeadas por el enemigo.

38 Vide BANCo de EsPaña, o. c., pág. 279.

39 Vide Conde, o. c., pág. 450, y Banco de España, o. c., pág. 274.

40 O. c., ya se ha estudiado su excepcional situación geográfica líneas atrás. 
El segundo de los niveles, el fraccionario, abarca los valores inferiores a 5 ptas. Para estos valores el gobierno se mostró pasivo y retardado.

Por desgracia las emisiones estatales para solucionar el problema llegaron tarde y las entidades locales ya habían tomado la iniciativa para mitigar las consecuencias de la pasividad gubernamental, como veremos más adelante. La República puso en circulación entre finales de 1937 y el año 1938 moneda metálica de 1 ptas. de latón (50.000.000 piezas), de $50(51.000 .000$ p) y de 25 (12.272.000 p.) cts. en cobre, de 10 (1.000 p.) y 5 (10.000.000 p.) cts. en hierro ${ }^{41}$; el Ministerio de Hacienda fabricó billetes de 1 ptas. ( 40.000 .000 billetes) y de 50 cts. $(40.000 .000$ b.) con fecha de 1937 y de 2 ptas. (30.000.000 b.) con fecha de 1938 que se pusieron en circulación el 18 de enero de 1938 para hacer frente a la falta de moneda metálica ${ }^{42}$. Este hecho, la emisión de billetes por parte del Ministerio de Hacienda, fue un acto innovador ya que hasta la fecha, 1937-38, no habia billetes de estado circulando, dejando de lado los certificados de plata de emisión 1935 que son un caso especial y sintomático del cambio que se avecina. Todo el circulante estatal, al empezar la guerra, era inferior a 25 ptas. y se acuñaba sobre metal con un valor-peso concreto; de forma que estas monedas tenian valor por sí mismas y avalaban los billetes del Banco de España que habia en circulación. Si tenemos en cuenta esto podemos considerar la medida del Ministerio de Hacienda para hacer frente a la falta de moneda metálica como extraordinaria ya que estos billetes de 0,50, 1 y 2 ptas. respectivamente no tienen valor por sí mismos ni aval metálico, su valor radica en el órgano emisor que los apoya. Acaba de nacer de facto la idea de una moneda convencional que no se corresponde con un valor metálico verdadero. ¿Contribuyó este hecho a desarrollar más aún la inflación o fue consecuencia de ésta? Dejemos la pregunta en el aire y sigamos con la descripción de las medidas estatales. De otro lado la Fábrica Nacional de Moneda y Timbre puso en circulación en 1938 unos discos de

41 Vide Calico, o. c., pág. 65; CAStan-Cayon, o. c., págs. 115-1151; VíCEnTI, o. c., páginas $76-78$.

42 Banco de España, o. c., pág. 340; vide Calico, o. c., pág. 68. 
cartón con timbres móviles o sellos postales con valores de 5 , 10,15 y 25 cts. para hacer frente a la penuria de pequeños valores $^{43}$. Creo que no es necesario que repitamos el comentario anterior sobre moneda irreal porque está a la vista el hecho.

Estas soluciones gubernativas estuvieron lejos de tener un alcance total y no bastaron para impedir que las comunidades locales siguieran usando sus propios paliativos ante la crisis. A pesar de que el Ministerio decretó el 6 de enero de $1938^{44}$ un plazo de un mes para retirar los valores, bonos, billetes y moneda no emitida por el gobierno, aludiendo que era una facultad que la constitución reservaba al estado, hubo reticentes y con posterioridad al decreto se siguió empleando esa solución local que abarcaba desde los vales de las tiendas a los billetes y monedas de ayuntamientos y demás centros de poder comarcal, provincial, etc. A este respecto son muy significativas las palabras de Calicó cuando dice que la orden no tuvo efectos inmediatos ${ }^{45}$; o las de la obra del Banco de España, más radicales. al decir que el decreto tuvo en la práctica escasa efectividad ${ }^{46}$; o la opinión expresada en las Actas del Consejo Municipal de Alcoy: "...mientras que en otras localidades desoyeron los requerimientos de las autoridades competentes y sigue circulando la moneda emitida..." ${ }^{47}$. Es más, el Ayuntamiento de Alcoy, en la misma sesión que acabamos de mencionar del 22 de agosto de. 1938, aprobó poner cierta cantidad de sus billetes municipales en circulación con posterioridad al mencionado decreto.

Concluyendo, podemos decir que las emisiones estatales y el decreto de enero de 1938 no surtieron los efectos esperados. El gobierno no supo o no pudo dar una pronta solución al proble-

43 Vicenti, O. C., pág. 79; vide Calico, o. c., pág. 69.

44 Gaceta de la República, 8 de enero de 1938.

45 Calico, o. c., pág. 69.

46 Banco de España, O. c., pág. 348.

${ }^{47}$ Sesión extraordinaria de 22 de agosto de 1938. 
ma fraccionario y cuando la dio lo hizo tarde. Más aún, las comunidades locales, cuando el estado central intentó llevar a cabo las medidas pertinentes, siguieron usando sus propias soluciones adoptadas con anterioridad, pese a lo explícito de la prohibición del gobierno republicano.

Respecto a las medidas del gobierno, José María Bricall opina de forma distinta a lo aquí expuesto. Ve las medidas del estado como un juego financiero lucrativo de éste y no como unas soluciones concretas a un problema ${ }^{48}$, tal vez debido a que su trabajo abarca una zona española de especiales necesidades financieras. Lo cierto es que apoya sus afirmaciones con suficiente documentación por lo que hay que tenerlo muy en cuenta a la hora de analizar el asunto que nos ha ocupado.

Las reacciones de los organismos locales ante la necesidad de numerario que estamos estudiando pudieron obedecer a varias causas. De un lado la imposibilidad del gobierno central para solucionar la carencia de moneda fraccionaria, o en zonas concretas la total falta de circulante, que obligó a los diversos organismos locales a paliar el problema por su cuenta ya que afectaba directamente a su economía entorpeciendo el consumo diario u otras transacciones comerciales. La obra del Banco de España da una visión general de todas estas soluciones ${ }^{49}$. De otro lado, siendo una causa mucho más hipotética, está el interés autonomista de los órganos locales y sus deseos de lucro con tales medidas. Los anarquistas, los sindicatos, la burguesía liberal de Cataluña y del País Vasco... pueden plantear sus reivindicaciones a través de la moneda; es más, pueden presentar una batalla contra el gobierno con la moneda. Unos ejemplos claros de lucro son los de las tiendas y los ayuntamientos. Las tiendas emiten vales que sólo se pueden gastar dentro de su lo-

48 Vide Bricall, J. M., Politica económica de la Generalitat (1936-1939) II. El sistema financier, Barcelona, 1979.

Quiero destacar que Bricall si que ve claramente, páginas 291-292, la retirada de la plata por parte del gobierno, cuestión que hemos estado intentando ver anteriormente con los presupuestos de Gil Farrés.

49 Vide 0 . C., págs. 281-349. 
cal; al entregar uno de esos vales al consumidor determinan que éste tenga que gastarlo allí y no en otra parte. Los ayuntamien. tos aún sacan mayores beneficios ya que venden sus billetes locales (puro papel) por billetes de curso legal (cheque-plata). Esta hipótesis conecta con uno de los planteamientos que el novelis. ta John Dos Passos tiene sobre la guerra civil española al opinar que los comunistas no lucharon sólo contra el fascismo sino que tuvieron que hacerlo contra sindicalistas, anarquistas, socialistas y la burguesía liberal catalana y vasca ${ }^{50}$. Creo oportuno recordar aquí unas palabras de Calicó sobre el tema: «...la emisión de monedas no responde siempre a una necesidad práctica, ya que la acción puede ser motivada por incitativos políticosociológicos. En la guerra civil española se registraron con frecuencia ambos estímulos...." ${ }^{51}$. ¿Contribuyeron estos planteamientos a que no se cumpliera eficazmente la orden del gobierno, 1938, de retirar toda moneda ajena a él?

Lós primeros en notar el colapso de la circulación monetaria fueron los comercios «que se veían imposibilitados de devolver cambios, y para ello, entregaban a sus clientes vales o abonos. El sistema era fácil, práctico y productivo para los emisores, debido al notable porcentaje que no se presentaban al reem. bolso. Todo ello dio pie a que los organismos regionales, ayuntamientos, consejos, sindicatos, comités políticos, colectividades obreras, unidades militares, cooperativas y economatos, emitiesen sus propios vales" ${ }^{52}$.

Pero estas medidas de tendencia autonómica sólo servirían para mitigar la carencia a nivel local, sin mayores alcances, ya que fuera del ámbito que domina la entidad emisora perdian todo valor. A este respecto son clarificadoras las palabras de $\mathrm{Fe}$ rrer Miró recogidas en las Actas del Consejo Municipal de

50 Vide The Theme is freedom, Nueva York, 1956, págs. 113-129, traducción al castellano Rojas, C. "Por qué perdimos la guerra", Barcelona, 1971, páginas 237-241.

51 O. c., pág. 64.

52 Cf. Calico, o. c., pág. 64. 
Alcoy ${ }^{53}$ al decir que los vales de locales comerciales sólo se pueden gastar en esos establecimientos; o el texto de las mismas Actas que aprueba la primera emisión de billetes en Alcoy: "Billete de circulación obligatoria en toda la jurisdicción municipal” ${ }^{54}$. ¿Qué pasaba si alguien intentaba usar estos valores fuera de su jurisdicción? Me imagino que serían rechazados, sin más. Esta entidad emisora, que determina el radio de acción del valor-moneda local, podía ir desde una tienda hasta una región amplia como la Generalitat de Cataluña. Para comprender este punto aconsejo que se vea la obra de Bricall ${ }^{55}$ en lo tocante a este tema. En dicha obra, Bricall, hablando de la moneda fraccionaria, sobre una base de 933 entidades emisoras, clasifica lo que él llama "unitats emissores" en organismos públicos (ferrocarriles, aguas, tiendas..., hasta 19 unidades); espectáculos y diversiones (47 unidades emisoias), y otros (bancos, empresas..., hasta 28). Concluye que hay un predominio de organismos públicos como unidades emisoras ${ }^{56}$.

Pues bien, la emisión de billetes y su puesta en circulación por parte del Ayuntamiento de Alcoy durante 1937 y 1938 con valores de una peseta y de veinticinco céntimos respectivamente ${ }^{57}$ tampoco es un caso aislado, forma parte de las reacciones de las comunidades locales contra la necesidad de moneda fraccionaria. Concreta nente entran dentro de lo que Bricall clasifica como organismos públicos al diferenciar las unidades emisoras vistas arriba.

Me parece que con lo que hasta aquí se ha dicho ya podemos comprender por qué se produjo la emisión de billetes loca-

53 Sesión extraordinaria de 5 de julio de 1937.

54 Ibid., 12 de julio de 1937.

55 O. c., págs. $49-74$ y 28 t- 286.

56 O. c., págs. $285-286$.

57 Primera emisión, 22 de julio de 1937; segunda emisión, 11 de octubre de 1937; circulación limitada de billetes locales desoyendo la prohibición del gobierno en 1938, 22 de agosto de 1938. 

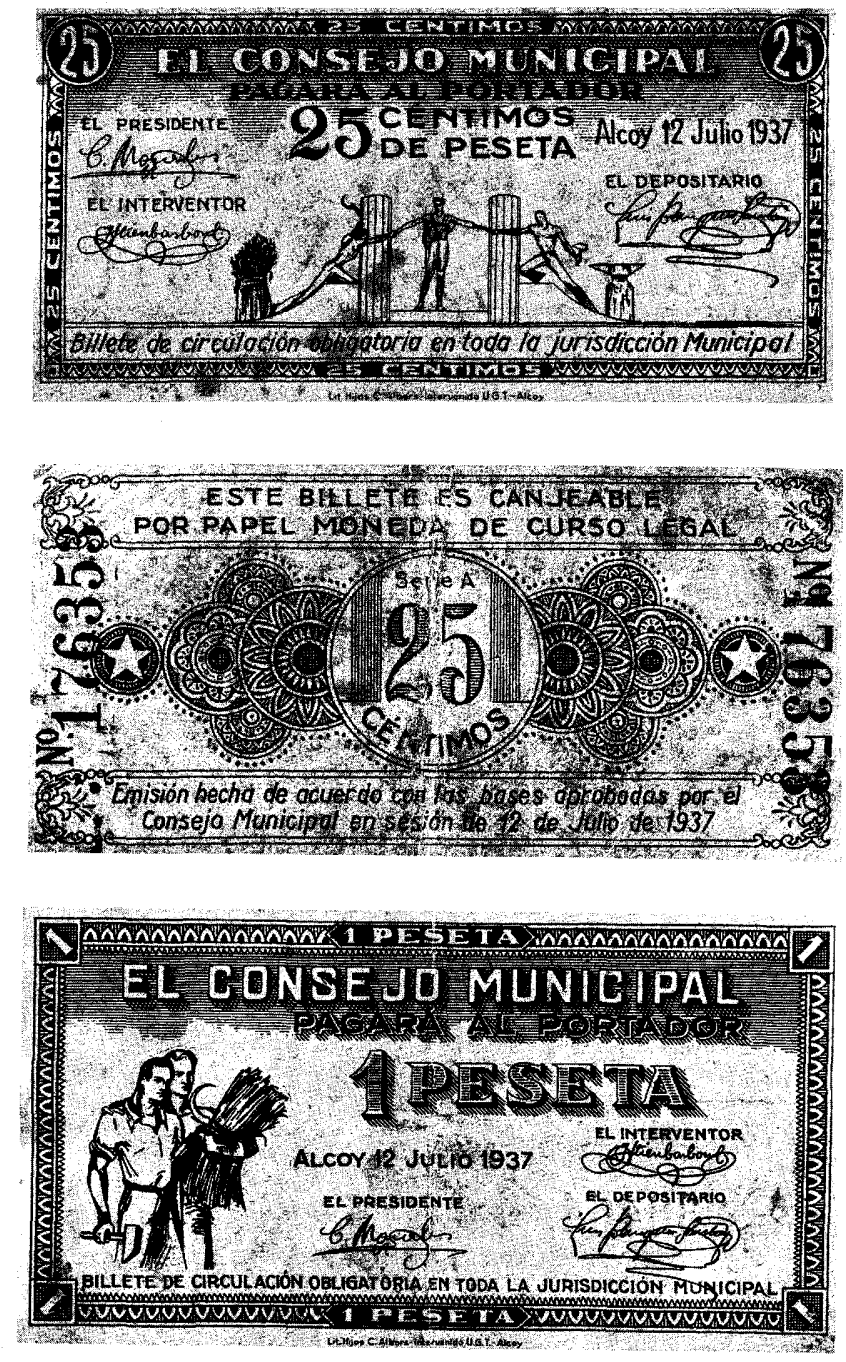

Billetes emitidos por el Consejo Municipal de Alcoy (Gentileza de D. Vicente Segura Espí) 
les en Alcoy. En la explicación de ello juegan una baza importante tanto la coyuntura económica como la bélica, social e, incluso, la ideológica de la España del momento. Pero lo que nos falta por ver es cómo se produce concretamente este hecho monetario en Alcoy. Para ello es preciso que rebusquemos entre los papeles del Archivo Municipal de Alcoy aquellos que tratan del asunto, como son las Actas del Consejo Municipal y la prensa de la época, y consultemos las obras de Berenguer ${ }^{58}$, Colo$\mathrm{ma}^{59}$ y Ramos ${ }^{60}$ que han mencionado la emisión alcoyana de billetes en sus respectivos trabajos; además de tener presentes los testimonios de las personas que vivieron la guerra.

Según Berenguer, la enojosa circunstancia que diariamente se experimentaba por falta de calderilla o moneda fraccionaria, se palió en Alcoy con el acuerdo adoptado en 12 de julio de 1937 por el Consejo Municipal, de emitir papel-moneda61.

El problema arrancaba desde mucho más allá de julio de 1937. A principios de dicho año Alcoy ya sufría las consecuencias económicas derivadas de la falta de circulante. El Diario de la Revolución, Humanidad, denunciaba los trastornos ocasionados por el atesoramiento de billetes y plata, y el no ingreso de dinero en los bancos, en su artículo titulado "Para normalizar la economía" ${ }^{62}$. Tales tesorizaciones eran lógicas en época de guerra y más si tenemos en cuenta todas las causas analizadas líneas atrás, a las que se añade, para el caso de Alcoy, el temor a las frecuentes confiscaciones ${ }^{63}$. Relatos de personas que vivieron aquellos tiempos confirman lo dicho contando cómo emparedaban o enterraban billetes y monedas buscando su seguri-

58 O. c., t. III, págs. 310-311 y 339-342.

59 O. c., págs. $301-302,331$ y $340-341$.

60 O. c., t. II, págs. 201-202.

61 Cf. Berenguer, o. c., t. III, págs. 310-311

62 Humanidad, 2 de enero de 1937.

63 Vide Coloma, o. c. 
dad. De otro lado, además de no ingresar dinero en los bancos, se produjeron masivas retiradas de capitales del Monte de Piedad de Alcoy ${ }^{64}$, tal vez con fines similares a los que llevamos vistos. Poco después el gobierno, por boca del mismo diario local ${ }^{65}$, desmentía que el oro español hubiese sido depositado en el extranjero. Puede que uno de los motivos que movieron al citado gobierno a dar este comunicado fuese el de tranquilizar a la población para que no tesorizara moneda metálica por esa causa; lo cual viene a confirmar más aún el problema de la acumulación de circulante por parte de particulares. Téngase también aquí presente que el estado tesorizó por su cuenta, como hemos intentado demostrar más arriba, por lo que el problema era mucho más grave de lo que aparentaba.

En mayo, el Consejo Municipal empezaba a tomar cartas en el asunto estudiándolo sin planteamientos concluyentes. Se pensó depositar 50.000 ptas. en la Caja Especial para hacer frente al problema del numerario ${ }^{66}$. Con todo ello aún sería necesario esperar hasta junio para que la carencia de moneda fraccionaria se estudiase seriamente. Digo lo de carencia fraccionaria porque las fuentes, desde este momento, sólo denuncian tal carencia. Es de suponer que las medidas del gobierno republicano, estudiadas anteriormente, ya habían surtido efecto en Alcoy; de forma que solamente quedaba el problema monetario a nivel de moneda inferior a 5 ptas.

En la Sesión Extraordinaria del 5 de julio de 1937 del Consejo Municipal de Alcoy saltó la chispa que desencadenaría las medidas tomadas frente a la crisis. En la misma se leyó una instancia firmada por el Presidente del Consejo Administrativo (Sección Camareros), J. Santamaría Ferrer, solicitando autorización para hacer vales equivalentes a moneda con el fin de amino-

64 Vide Coloma, Crónica del Monte de Piedad de Alcoy, Alcoy, 1977, páginas 253 269.

65 Humạnidad, 20 de enero de 1937.

66 Actas Permanente Consejo Municipal, Sesión ordinaria 17 de mayo de 1937. 
rar el problema del cambio en sus establecimientos. A esto se opuso el consejero Ferrer Miró, del Partido Comunista:

...porque prácticamente se ha visto, como por ejemplo en Valencia, que es un fracaso, siendo el procedimiento molesto y un nido de pleitos. Además es inmoral, porque el obrero que se gasta unos céntimos en un vermouth o un refresco y entrega un papel de cinco pesetas, como se le dan vales, ya no puede comprar otras necesidades v tiene que invertir el resto del duro en el mismo establecimiento..

Quiero destacar de las palabras del consejero Miró una cosa: que el obrero puede entregar un papel de 5 ptas. porque lo posee. Recordemos aquí aquellos certificados de plata de 5 y 10 ptas. estudiados líneas atrás y comprobemos que aquellas medidas que desarrollaba el gobierno central ya estaban funcionando en el Alcoy del momento. Por ello la crisis no afectaría a los valores iguales o superiores a 5 ptas. en el caso que nos ocupa.

De otro lado el consejero Barberá, de la CNT, entregó un biIlete que circulaba en Tarragona como ejemplo a adoptar. Pretendía con ello que el propio Ayuntamiento fuese el emisor de los vales y no ningún particular.

El Presidente del Consejo ${ }^{67}$ propuso que se encargara el análisis del problema a la Comisión de Hacienda del municipio. Al final el asunto pasó a la Comisión Municipal de Hacienda. Pero, con anterioridad, el consejero Ferrer Jordá, de la CNT, matizó que se diera pronta solución a esta carencia fraccionaria que tanto se agudizaba. De otro lado el consejero López, de la UGT, puso de relieve que los vales causarían inflación. A tal efecto sería interesantísimo realizar un trabajo sobre la relación existente entre los billetes locales, vales, y demás y el aumento de los precios; y comprobar, además, si la emisión de toda esta moneda local es resultado de la inflación. Recordemos aquí una de las causas que desataron la crisis monetaria, la cual vimos en el planteamiento general del tema. Con lo que podriamos concluir que la emisión de billetes locales agudiza la inflación dentro de los municipios. Este planteamiento, hasta que no se realice el trabajo propuesto, no deja de ser una hipótesis.

67 Cándidó Morales Cots, de la C. N. T. (Berenguer, o. C., t. III, pág. 291). 
Poco después de celebrarse esta Sesión Extraordinaria del Consejo Municipal, el diario Humanidad apoyó la postura general de los consejeros que se oponían a los vales de los gremios y se decantaban por la emisión de billetes locales para sustituir la falta de circulante de plata, cobre y níquel ${ }^{68}$.

La Comisión de Hacienda se reunió el día 9 de julio de 1937 en que se acordó la propuesta a hacer ante el Consejo a celebrar el 12 del mismo mes y año ${ }^{69}$.

El diario Humanidad de nuevo respaldó las decisiones de la Comisión de Hacienda, poniendo como excusa de las emisiones de billetes locales que se proponía la pasividad del gobierno para fabricar monedas de 1 pta. y de 50 cts.; matizando que cuando saliera la emisión del gobierno la del Ayuntamiento debía retirarse $^{70}$.

En la Sesión Extraordinaria del Consejo Municipal del 12 de julio de 1937 se aprobó la propuesta de la Comisión Municipal de Hacienda cuyo texto resume muy bien el tema:

HACIENDA. - MONEDA FRACCIONARIA. - Igualmente fue aprobada por unanimidad una proposición de la Comisión de Hacienda, cuyo tenor literal es como sigue:

"Los que suscriben, Presidente y Vocales de la Comisión Municipal de Hacienda, que autorizan, prestando la debida atención a los problemas que los actuales momentos plantean a todos los organismos oficiales, han tenido el máximo interés en dedicarse al estudio del que representa la falta de moneda fraccionaria, que, acaparada por los seres desaprensivos y por los enemigos del régimen imposibilita puedan desenvolverse con normalidad las ventas comerciales y la marcha de algunas industrias, como cafés, bares y otros establecimientos análogos. Estos inconvenientes han motivado que, en algunos comercios e industrias cuando no se puede atender a la clientela con el cambio de moneda fraccionaria, se emitan unos vales o tikets por el importe del cambio. Y este procedimiento, dejado al libre arbitrio de los establecimientos industriales o comerciales, significa un grave perjuicio para la economía individual y colectiva, porque se obliga al público a un excesivo gasto y se le priva además de la iniciativa de poder efectuar sus

68 Humanidad, 8 de julio de 1937.

69 Datos sacados de la sesión extraordinaria del 11 de octubre de 1937, Actas del Consejo Municipal.

70 Humanidad, 11 de julio de 1937. 
compras en aquellos establecimientos que estime más conveniente, haciendo también que, por falta de una garantía en el valor de los vales-monedas expedidos sin ningún controlamiento, el coste de algunos artículos se eleve a proporciones inconcebibles. Seria prudente, para evitar todo esto, que el Gobierno, asi como ha hecho una emisión especial de papel-moneda de cinco y diez pesetas, la hiciera también de moneda fraccionaria, con lo que se haria fracasar el malintencionado propósito de los acaparadores de las monedas de plata y cobre, y se darian facilidades para que los intereses del público, y del comercio en general, se vieran debidamente atendidos. Pero mientras no lo haga el Gobierno, los Consejos Municipales o Provinciales no deben ni pueden desatender este grave problema de las facilidades del cambio de la moneda fraccionaria y, a tal efecto, en algunas localidades, sus Consejos ya han emitido papel-moneda fraccionaria. Por todo ello, con unánime criterio, tenemos el honor de presentar a la aprobación del Pleno del Consejo la siguiente. PROPOSICION. Que, para evitar que el arbitrio de los establecimientos industriales y comerciales puedan emitirse vales-moneda para el cambio que el importe de las ventas y operaciones que realicen, sin la debida garantía de valor efectivo, el Consejo lleve lo más rápidamente posible a efecto una emisión de papel-moneda fraccionaria, garantizándola con el correspondiente depósito de papel del Estado por valor de cien mil pesetas, obligando a todos los establecimientos del comercio y la industria, a que de la Depositaría de los Fondos Municipales retiren determinada cantidad de dicho papel-moneda, garantizado por el municipio, previo el pertinente depósito en papel-moneda del Estado y, por medio de Bandos de la Presidencia y de cuantos medios de divulgación existan, se requiere al público para que, en cumplimiento de las instrucciones que se dicten, se provea de papel-moneda del Municipio para las facilidades de sus compras. De las cien mil pesetas referidas, se emitirán inmediatamente cincuenta mil pesetas y, para realizar la emisión de las segundas cincuenta mil pesetas, será necesario previo y nuevo acuerdo del Consejo; la expresada emisión será distribuida de la siguiente forma: sesenta mil pesetas emitidas en papel-moneda de a (veinticinco céntimos); y cuarenta mil pesetas emitidas en papel-moneda de a una peseta. El papel de la primera emisión, o sea la de veinticinco céntimos, tendrá en total un tamaño de $8 \times 4$ ctms., correspondiendo solamente a la parte impresa 7 y $1 / 2$ por 3 y $1 / 2$ centímetros de forma que vengan centrados y, dejen margen en blanco de la diferencia, distribuida por partes iguales, entre las cuatro aristas del papel. La emisión de una peseta tendrá en total un tamaño de $9 \times 5$ ctms. correspondiendo a la parte impresa $8 \times 4 \mathrm{ctms}$. centrado en la misma forma que los anteriores. Estos billetes, estarán impresos con las siguientes inscripciones. En el anverso se pondrá: "El Consejo Municipal pagará al portador veinticinco céntimos de peseta" (o una peseta según de la emisión que se trate), en la parte superior. En el centro, irá un grupo alegórico de la Industria, Comercio y Agricultura o algún emblema alusivo al Municipio. Al lado izquierdo se dejará un espacio en blanco para estamparse un sello en seco. En la parte inferior se pondrá: Alcov. 12 de Julio de 1937»71.

\section{Hay muchas cosas importantes en el texto; pero para no perdernos en consideraciones repetitivas o superfluas destaca-}

71 Actas del Consejo Municipal, sesión extraordinaria de 12 de julio de 1937. 
ré sólo lo más relevante. Por un lado la doble línea justificativa de la emisión de billetes y por otro la cantidad de los mismos. Las dos corrientes justificativas son el paliar la falta de acción gubernativa ante el problema, sin perjuicio del Estado, y la protección de la economía individual y colectiva, en concreto la igualdad de posibilidades de venta y compra para todos. La cantidad de billetes en pesetas es de 100.000 ptas., distribuidas de la siguiente forma: 40.000 ptas. para los billetes de pesetas y 60.000 ptas. para los de venticinco céntimos.

La impresión de los billetes se realizó en la litografía Hijos de C. Albors. Intervenida U.G.T. Alcoy ${ }^{72}$.

Fueron puestos en circulación el 16 de agosto, anulándose desde este día los vales ${ }^{73}$.

Al parecer estas medidas tuvieron efectos positivos hasta septiembre; fecha en que J. Santamaría Ferrer volvió a presentar una instancia, que se rechazó, solicitando permiso para emitir vales $^{74}$. Cabe preguntarse si lo hizo por motivos egoístas o por necesidades reales. Lo cierto es que el Consejo Municipal aprobó en octubre del mismo año 1937 la propuesta de la Comisión de Hacienda para una segunda emisión, pese a que con anterioridad se había ampliado la emisión del 12 de julio de 1937, como refiere el texto de las Actas del citado octubre:

Próxima a agotarse la emisión de billetes de moneda fraccionaria acordada por este..., emisión que no sólo comprendía la tirada de cuarenta mil billetes de a una peseta y doscientos cuarenta mil billetes de a veinticinco céntimos de peseta, sino también tres mil billetes más de los de la segunda que en sesión posterior y a propuesta verbal del Consejero de Hacienda Francisco López Cortés se acordó fuesen puestas en circulación, estima esta Comisión procede llevar a la práctica nueva emisión de billetes de ambas clases, con objeto de que puedan continuar desenvolviéndose con normalidad las ventas comerciales y la marcha de algunas industrias, como cafés... Por todo ello, con unánime criterio tiene el honor de presentar... la si. guiente -Proposición. -Que el consejo lleve lo más rápidamente a efecto

72 Berenguer, o. c, pág. 311.

73 Cf. Ramos, t. III, o. c., pág. 202.

74 Actas del Consejo Municipal, sesión extraordinaria de 6 de septiembre de 1937. 
una segunda emisión de papel-moneda fraccionaria garantizándola como en la primera que hizo con el correspondiente depósito de papel del Estado por valor de ciento veinte mil pesetas, en igual forma, tamaños, coloridos y demás circunstancias con que se hizo la primera emisión variando únicamente la letra de la serie que, en la primera emisión fue "A" y en esta segunda emisión tiene que ser " $B$ " y emitiéndose setenta y cinco mil pesetas; en papel moneda de a una peseta y cuarenta y cinco mil pesetas en papel moneda de a veinticinco céntimos... ${ }^{75}$

Las diversas medidas del Consejo Municipal de Alcoy solucionaron el problema de la circulación fraccionaria. Es significativo el completo silencio que las fuentes guardan al respecto. Pero aún es más significativa la opinión expresada por la Comisión Municipal de Hacienda en agosto de 1938 en el preámbulo de la proposición presentada al Consejo Municipal:

...Que la normalidad en el funcionamiento de los establecimientos comerciales e industriales y de las demás actividades quedó garantizada con dichas emisiones hasta el 15 de marzo del presente año, en que fueron retiradas de la circulación por orden de la Superioridad...76.

Pero como apunta el texto anterior la carencia de moneda fraccionaria volverá a plantearse en Alcoy a raíz de la intervención estatal. El decreto de 6 de enero de 1938 dado por el Minis. terio de Hacienda y Economía ${ }^{77}$ ordenaba, aludiendo a las potestades constitucionales reservadas al estado con respecto a la emisión de moneda, retirar todo valor-moneda ajeno a él en el plazo de un mes. A tal efecto el gobierno emitió valores fraccionarios. Todo ello ya se ha visto en el planteamiento general del tema, por lo que huelga repetirlo.

El Consejo Municipal de Alcoy, basándose en el informe de la Comisión Municipal de Hacienda, aprobado el 31 de enero de $1938^{78}$, se dispuso a cumplir el decreto preparando la retirada de las 229.250 ptas. de billetes locales en circulación. Para ello se daba un plazo, para reembolsar con moneda o billetes del es-

75 Ibid., 11 de octubre de 1937.

76 Ibíd., 22 de agosto de 1937.

77 Gaceta de la República, 8 de enero de 1938.

78 Actas del Consejo Municipal, sesión extraordinariáa de 31 de enero de 1938. 
tado o del Banco de España los billetes municipales, que expiraban el 5 de febrero del mismo año; se preveia aumentar el personal para los pagos; y dar la publicidad necesaria. El 1 de febrero el diario Humanidad publicó el edicto ${ }^{79}$.

Sin embargo, como dice Coloma, la retirada de la circulación de la moneda fraccionaria emitida por el Ayuntamiento, iba a acarrear serias complicaciones y problemas. Así debió verlo el presidente del Consejo, porque se dirigió por telegrama al gobernador civil y al delegado de Hacienda, exponiéndoles el caso, contestanto ambas autoridades que autorizaban la circulación "hasta tanto se reciba la cantidad necesaria para sustituir a la misma, lo cual se anunciará oportunamente» ${ }^{80}$.

A mediados de febrero, "en vista de las numerosas órdenes telegráficas cursadas a este Consejo por Autoridades superiores, sobre la forma en que ha de procederse a retirar la moneda fraccionaria", la Comisión Municipal de Hacienda propuso al pleno del Consejo que facultara al titular de Hacienda para que procediera como las circunstancias aconsejaran. El Consejo Municipal aprobó por unanimidad la proposición ${ }^{81}$. En la misma Sesión Municipal se aludía a la falta de moneda fraccionaria del estado que sustituyera a la local, lo cual traducía la orden gubernativa en desconcertante y confusa. Resultaba imposible llevar a efecto tal decreto.

En febrero, «el 24, el consejero de Hacienda en funciones, Cristóbal Vicéns Company, repetía el edicto del presidente del Consejo (decreto del 1 de febrero), puntualizando que el $10 \mathrm{del}$ viniente mes de marzo, serían canjeados los billetes de moneda fraccionaria emitida por el Ayuntamiento, y significando que la circulación del referido papel-moneda cesaría el día 28 de febrero, a todos los efectos. Pero la retirada definitiva de estos billetes alcoyanos no se logró hasta el 15 de marzo, como refiere el

79 Humanidad, 1 de febrero de 1938.

80 Cf. Coloma, o. c., pág. 331.

${ }^{81}$ Actas del Consejo Municipal, sesión extraordinaria de 14 de febrero de 1938. 
texto de las Actas del Consejo Municipal del 22 de agosto de 1938.

Ello volvió a causar, a corto plazo, problemas para la circulación de moneda fraccionaria. La retirada de las dos emisiones locales junto a la escasa moneda estatal, que además desaparecía a causa de recientes tesorizaciones de la misma, obligó a que se pusiese en circulación parte de la segunda emisión de billetes locales retirados con anterioridad, según propuesta de la Comisión de Hacienda aprobada por el Consejo Municipal. Esta alegaba que el gobierno no había sancionado a los que no cumplieron el decreto del 6 de enero, que los particulares volvían a emitir vales, con las consecuencias subsiguientes, uniendo a ello la falta de moneda fraccionaria estatal. La propuesta en cuestión reza como sigue:

...se permite proponer al Consejo Municipal lo siguiente: $1 .^{\circ}$ Que ponga en circulación 3.000 billetes de una peseta y 36.000 de veinticinco céntimos de pesetas, que representan 3.000 y 9.000 pesetas respectivamente, y proceden de las dos emisiones a que antes se hace referencia. Dichos billetes tienen la numeración que se detalla:

De una peseta. Números del 68.001 al 69.000 - Serie B

De una peseta. - Números del 33.001 al 35.000 -.-

De 0,25 peseta. - Números del 144.001 al 180.000 - Serie B. 2. ${ }^{\circ}$ Estos billetes llevarán estampado un sello en el que se leerá "Consejo Municipal", para establecer la debida diferencia entre los mismos v los que circularon anteriormente que carecen en absoluto de valor ${ }^{82}$

Parece ser que estas medidas obtuvieron unos resultados satisfactorios y, desde ahora ya no volveremos a oír hablar de la falta de circulante fraccionario en Alcoy.

La circulación de estas 12.000 ptas. en billetes municipales terminó de forma fraudulenta al finalizar la guerra. La Comisión Gestora les negó todo valor al estar avaladas por billetes no válidos. Ello se hizo patente en la "Resolución de la situación financiera del Ayuntamiento con motivo de las disposiciones sobre circulación fiduciaria" diciendo que hay 1.160.069,72 ptas. de billetes rojos carentes de valor ${ }^{83}$. Con ello el gran perjudicado

82 Este texto lo transcribe completo Berenguer, O. c., págs. 340-342.

83 Actas de la Comisión Gestora, sesión extraordinaria de 14 de abril de 1939. 
fue el pueblo alcoyano que se quedó con unos papeles impresos testigos de una época. Epoca en que el Consejo Municipal de Alcoy decidía si cumplía o no el decreto del 6 de enero de 1938 del Ministerio de Hacienda y Economía; resolución gubernativa que acebó infringiendo en agosto del mismo año con lo que patentiza una autonomia que tal vez ayude a explicar la proliferación de emisiones locales republicanas. Epoca en que se fomentó el truque, agudizado por la escasez de muchos productos ${ }^{84}$, que testifican personas que lo vivieron. Epoca en la que la gente tuvo que responsabilizarse de los fallos del gobierno y paliarlos. Epoca que marcó el fin de una estructura monetaria caduda, basada en el peso del metal de la moneda, y abrió las puertas a la nueva PESETA esencialmente fiduciaria. Epoca, por último, de gran trascendencia para nuestra historia monetaria porque con ella empieza fácticamente la concepción que tenemos actualmente de la moneda, nuestra peseta devaluada ${ }^{85}$.

84 Vide Coloma y Berenguer en sus o. $C$.

85 Digo lo de "fácticamente" porque, en sí, la crisis monetaria española empezó en la década de 1880 (vide VICENS, o. C., pág. 103), pero no se reconoció de cara al interior hasta este momento. 
EVOLUCION DE LA CIRCULACION MONETARIA DE BILLETES ALCOYANOS ENTRE ENERO DE 1937 Y ABRIL DE 1939

\begin{tabular}{|c|c|c|c|c|}
\hline FECHA & VALORES & POTENCIAL* & SERIES & TOTAL * \\
\hline $\begin{array}{c}\text { Emisión de } 12 \text { de } \\
\text { julio de } 1937\end{array}$ & $\begin{array}{r}25 \text { cts. } \\
1 \text { pta. }\end{array}$ & $\begin{array}{r}240.000 \\
40.000 \\
\end{array}$ & $\begin{array}{l}\text { A } 1 \text { a } 240.000 \\
\text { A } 1 \text { a } 40.000 \\
\end{array}$ & $\begin{array}{r}240.000 \\
40.000 \\
\end{array}$ \\
\hline $\begin{array}{r}\text { Ampliación agosto } \\
\text { septiembre } 1937\end{array}$ & $\begin{array}{r}25 \text { cts. } \\
1 \text { pta. }\end{array}$ & $\begin{array}{r}25.000 \\
3.000 \\
\end{array}$ & $\begin{array}{l}\text { A } 240.001 \text { a } 265.000 \\
\text { A } 40.001 \text { a } 43.000\end{array}$ & $\begin{array}{r}265.000 \\
43.000 \\
\end{array}$ \\
\hline $\begin{array}{l}\text { Emisión de } 11 \text { de } \\
\text { octubre de } 1937\end{array}$ & $\begin{array}{r}25 \text { cts. } \\
1 \text { pta. }\end{array}$ & $\begin{array}{r}180.000 \\
75.000 \\
\end{array}$ & $\begin{array}{l}\text { B } 1 \text { a } 180.000 \\
\text { B } 1 \text { a } 75.000 \\
\end{array}$ & $\begin{array}{l}445.000 \\
118.000 \\
\end{array}$ \\
\hline \multicolumn{5}{|c|}{$\begin{array}{l}15 \text { de marzo de 1938: se retiran de la circulación todos los billetes } \\
\text { Decreto de } 6 \text { de enero de } 1938 \text { - Gobierno Republicano }\end{array}$} \\
\hline $\begin{array}{l}\text { Nueva circulación } \\
22 \text { de agosto } \\
\text { de } 1938 \\
\end{array}$ & $\begin{array}{l}25 \text { cts. } \\
1 \text { pta. }\end{array}$ & $\begin{array}{r}36.000 \\
3.000\end{array}$ & $\begin{array}{lrr}\text { B } & 114.001 \text { a } & 180.000 \\
\text { B } & 33.001 \text { a } & 35.000 \\
\text { B } & 68.001 \text { a } & 69.000 \\
\end{array}$ & $\begin{array}{r}36.000 \\
3.000 \\
\end{array}$ \\
\hline
\end{tabular}

(*) El potencial y el total se expresan en número de piezas.

FUENTE: Actas del Consejo Municipal de Alcoy, de 1937 a 1939. 


\section{GRAFICO ।}

\section{EVOLUCION DEL POTENCIAL DISPONIBLE DE PIEZAS METALICAS DE UNA PESETA ENTRE 1868 Y 1939 (SOLO MONEDA ESTATAL)}

\section{MILLONES DE PESETAS}

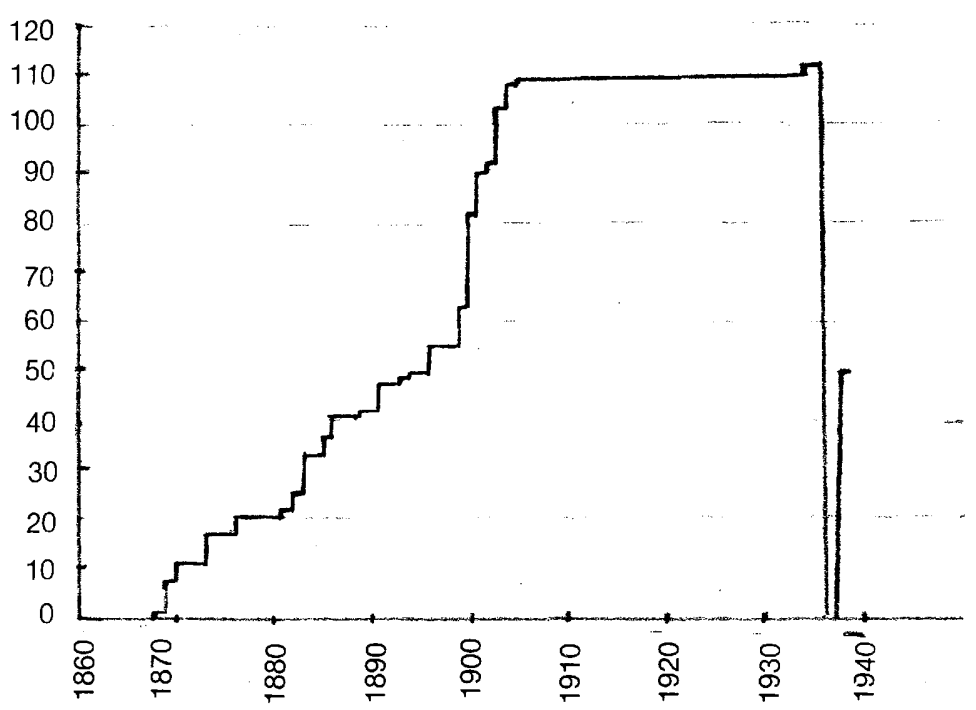

FUENTE: CASTAN-CAyON, o. c., para las cantidades, págs. 1121-1151. 


\section{GRAFICO //}

EVOLUCION DEL POTENCIAL DISPONIBLE DE PIEZAS DE 5, 2, 1 y 0,5 PESETAS

EN LA ESPAÑA REPUBLICANA ENTRE 1936 Y 1939 (SOLO MONEDA ESTATAL)

MILLONES DE PIEZAS
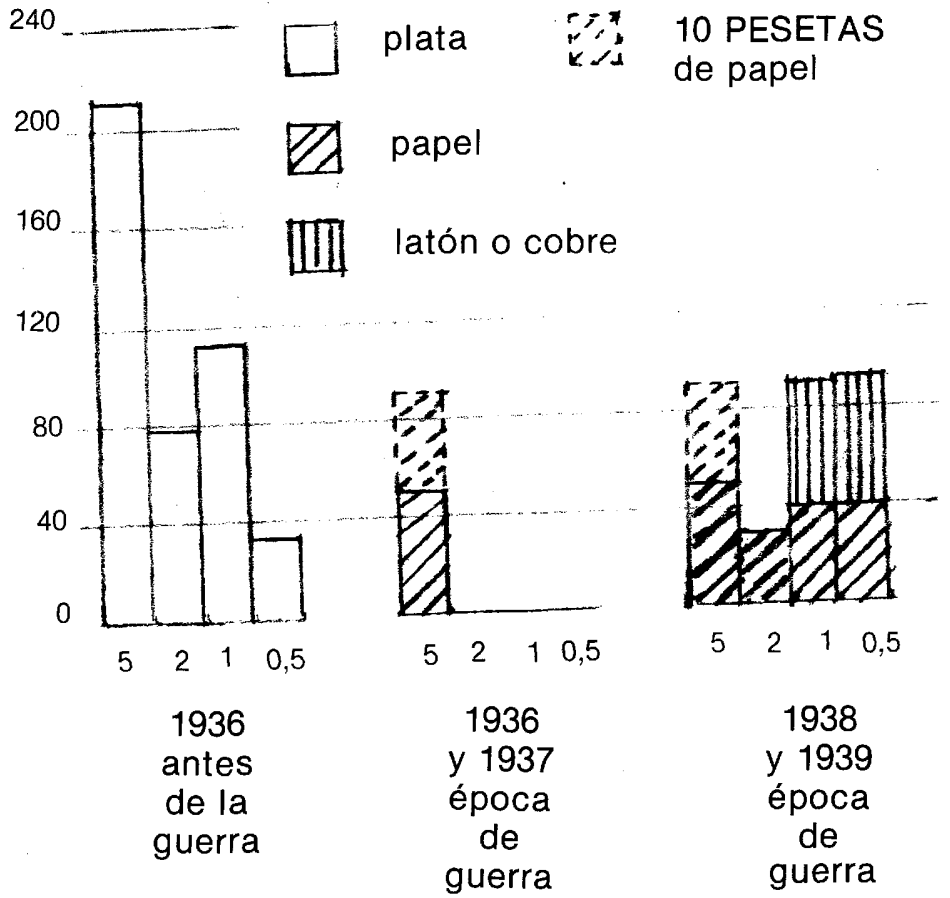
de papel

5210,5
1938
y 1939
época
de
guerra

fuente: Banco de España, o. c., págs. 275 y 279 ; Calico, o. c.; Castan-Cayon, o. c. 